Article

\title{
Analysis of Ionospheric Vertical Total Electron Content before the 2014 Mw8.2 Chile Earthquake
}

\author{
Weiping Jiang ${ }^{1, *}$, Yifang Ma ${ }^{1}$, Xiaohui Zhou ${ }^{2}$, Zhao Li ${ }^{3}$, Xiangdong An ${ }^{1}$ and Kaihua Wang ${ }^{1}$ \\ 1 GNSS Research Center, Wuhan University, 129 Luoyu Road, Wuhan 430079, China; yfangma@whu.edu.cn \\ (Y.M.); xdan@whu.edu.cn (X.A.); wkh651010@126.com (K.W.) \\ 2 School of Geodesy and Geomatics, Wuhan University, 129 Luoyu Road, Wuhan 430079, China; \\ xhzhou@sgg.whu.edu.cn \\ 3 Faculté des Sciences, de la Technologieet de la Communication, University of Luxembourg, 6, rue Richard \\ Coudenhove-Kalergi, 1359 Luxembourg City, Luxembourg; zhao.li@uni.lu \\ * Correspondence: wpjiang@whu.edu.cn; Tel.: +86-027-6877-8985
}

\begin{abstract}
This paper studies ionospheric vertical total electron content (VTEC) variations before the 2014 Mw8.2 Chile earthquake. VTEC derived from 14 GPS (Global Positioning System) stations and GIM (Global Ionospheric Map) were used to analyze ionospheric variations before the earthquake using the sliding interquartile range method, and results showed that significant positive VTEC anomalies occurred on 28 March. To explore possible causes of these anomalies, effects of solar and geomagnetic activities were examined, and VTEC variations during 17 March to 31 March in 2009-2013 were cross-compared. Also, VTEC for a full year before the earthquake was investigated. Results indicated that these anomalies were weakly associated with high solar activities and geomagnetic storms and that these anomalies were not normal seasonal and diurnal variations. An analysis of the spatial distribution of the observed anomalies was also presented, and it demonstrated that anomalies specifically appeared around the epicenter on 28 March. It suggests that observed anomalies may be associated with the subsequent Chile earthquake. Equatorial anomaly variations were analyzed to discuss the possible physical mechanism, and results showed that the equatorial anomaly unusually increased on 28 March, which indicates that anomalous electric fields generated in the earthquake preparation area and the meridional wind are possible causes of the observed ionospheric anomalies.
\end{abstract}

Keywords: ionosphere; vertical total electron content (VTEC); seismo-ionospheric anomaly

\section{Introduction}

Since the 1960s, a multitude of studies have identified abnormal variations of ionospheric parameters before many large earthquakes [1-8]. In recent years, GPS, with numerous worldwide and regional networks, has created a potentially powerful tool to investigate ionospheric TEC variations. Many researchers analyzed GPS TEC variations before devastating earthquakes worldwide, and suggested that GPS TEC could be used to detect possible ionospheric anomalies associated with subsequent earthquakes. For instance, Zhou et al. used 22 GPS stations in China to study VTEC variations during the Wenchuan earthquake, and the results indicated that VTEC around the epicenter increased both 9 and 3 days before the earthquake and decreased 6 days before the earthquake [9]; Yao et al. analyzed ionospheric variations occurring before the $2011 \mathrm{Mw} 9.0$ Japan earthquake, and proposed that the ionospheric anomaly occurring on 8 March might be a precursor of the earthquake [10]; Ho et al. investigated the ionospheric variations using TEC and electron density during the 2010 M8.8 Chile earthquake, and the results showed that TEC and electron density increased 9 to 19 days before the earthquake and specifically over the epicenter [11].

Although there are many papers reporting the identification of ionospheric anomalies before earthquakes, it remains controversial whether these anomalies are actually related to forthcoming earthquakes [12-16]. There was no statistically significant correlation between TEC anomalies and 
earthquakes in Southern California from 2003 to 2004 [13]. Masci suggested that the statistical analysis of Kon et al. was not reliable because it was influenced by global geomagnetic events [14, 17]. Ovalle et al. concluded that the observed NmF2 and TEC anomalies could not be unambiguously related to the 2010 M8.8 Chile earthquake [15]. To validate the relationship between ionospheric anomalies and earthquakes in response to the controversy, several studies have been undertaken to be expected to obtain more credible results. For example, Le et al. selected 736 globally distributed $M \geq 6.0$ earthquakes occurring during 2002-2010, conducted a statistical study of the pre-earthquake ionospheric TEC anomalies and the results demonstrated that TEC anomalies occurring just a few days before the earthquakes were probably associated with the forthcoming earthquakes [5]; to isolate ionospheric anomalies associated with the $2011 \mathrm{Mw} 9.0$ Japan earthquake, He et al. eliminated the nonlinear effect from solar radiation using a wavelet decomposition algorithm, found that the extracted TEC had a good correlation with the solar EUV26-34 and the F10.7, and the results show that this algorithm is effective and practical to remove background in seismo-ionospheric analysis [18]; Le et al. adopted the empirical and theoretical ionospheric models to check whether ionospheric anomalies before the $2011 \mathrm{Mw} 9.0$ Japan earthquake were only caused by the severe solar radiation [19]. Additionally, the possible seismo-ionospheric physical mechanism has been examined in many studies. Quite a few papers have proposed that anomalous electric fields generated in earthquake preparation areas may have caused the ionospheric disturbances [20-22].

An Mw8.2 earthquake occurred at 23:47:31.5UTC in Chile $\left(19.70^{\circ} \mathrm{S}, 70.81^{\circ} \mathrm{W}\right)$ on 1 April 2014 at a depth of $10 \mathrm{~km}$ (Figure 1). In this study, VTEC from 14 GPS stations and GIM VTEC were analyzed using the sliding interquartile range method. To correct for solar and geomagnetic activities, ionospheric anomalies induced by high solar radiation and geomagnetic storms were removed from the analysis. Furthermore, to determine the possible causes of the observed ionospheric anomalies, VTEC variations over the epicenter during 17 March to 31 March in 2009-2013 were examined. Also, VTEC for a full year before the earthquake was analyzed. Moreover, the spatial distribution of VTEC anomalies was examined and VTEC variations before $67 \mathrm{Mw} \geq 6.0$ earthquakes over the $\left(6^{\circ}-39^{\circ} \mathrm{S}\right.$; $60^{\circ}-78^{\circ} \mathrm{W}$ ) area in $2004-2013$ were statistically studied. Finally, the possible physical mechanism for ionospheric anomalies occurring before the earthquake was explored.

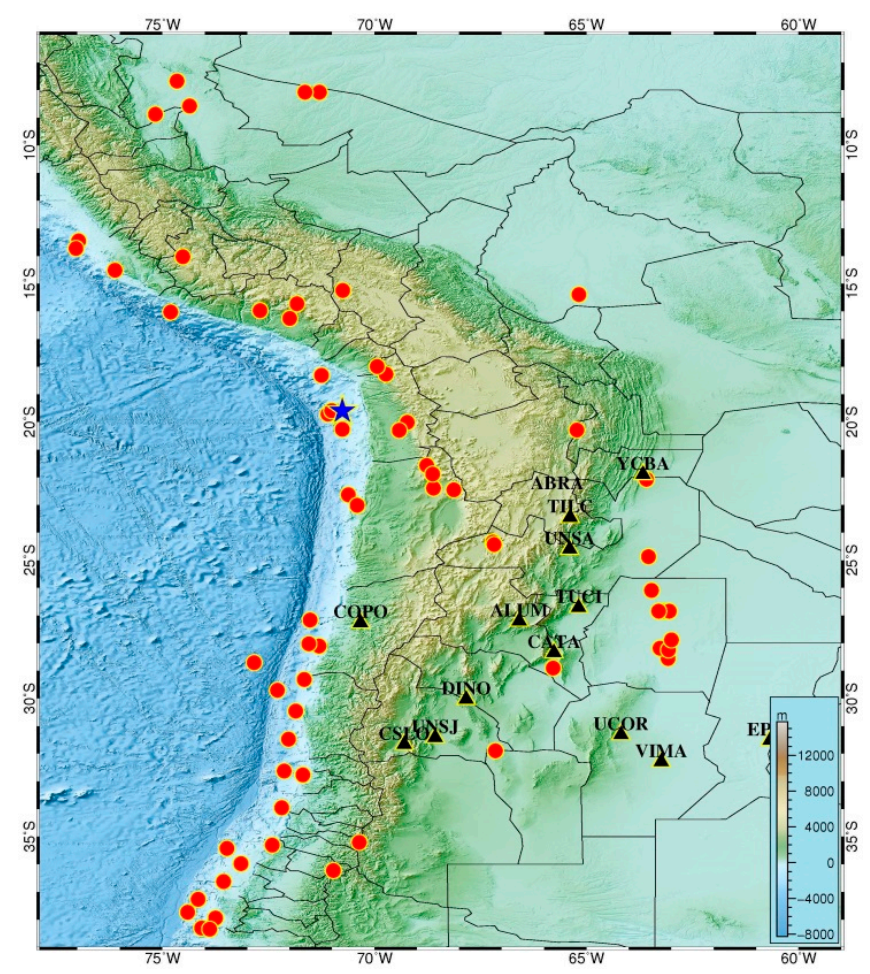

Figure 1. Locations of the epicenter of 2014 Mw8.2 Chile earthquake (blue star), $67 \mathrm{Mw} \geq 6.0$ earthquakes (red dots) during 2004 to 2013 and 14 GPS stations (black triangles). The earthquakes are selected from the Global CMT (Centroid Moment Tensor) Project, (http://www.globalcmt.org/). 


\section{Data and Analysis}

\subsection{Data source}

Data from 14 GPS stations provided by Instituto Geográfico Nacional (IGN) from Argentina at a 15-s sampling rate were used to calculate VTEC. Figure 1 shows locations of 14 GPS stations, and a detailed catalog is given in Table 1. In this study, VTEC time series were calculated over each station from 2 March to 1 April 2014 and a detailed discussion of the accuracy of VTEC is provided by [13]. There are some discontinuities in VTEC time series derived from GPS data because of the presence of gross errors or gaps. To avoid these discontinuities and to ensure the identical time interval in VTEC time series, we choose $15 \mathrm{~min}$ resolution VTEC value to analyze. The associated time is in UTC.

Table 1. GPS stations in the East-South sector from epicenter.

\begin{tabular}{cccccc}
\hline Stations & Longitude $\left({ }^{\circ} \mathbf{W}\right)$ & Latitude $\left({ }^{\circ} \mathbf{S}\right)$ & Stations & Longitude $\left({ }^{\circ} \mathbf{W}\right)$ & Latitude $\left({ }^{\circ} \mathbf{S}\right)$ \\
\hline ABRA & 65.69 & 22.60 & TILC & 65.39 & 23.45 \\
ALUM & 66.59 & 27.20 & YCBA & 63.67 & 21.90 \\
CATA & 65.77 & 28.34 & UCOR & 64.19 & 31.31 \\
COPO & 70.33 & 27.26 & UNSA & 65.40 & 24.60 \\
CSLO & 69.30 & 31.66 & UNSJ & 68.57 & 31.41 \\
DINO & 67.84 & 30.03 & VIMA & 63.24 & 32.29 \\
EPSF & 60.67 & 31.51 & TUCI & 65.19 & 26.71 \\
\hline
\end{tabular}

Generally GIM is derived using GNSS observations from hundreds of global stations [23]. The GIM covers $\pm 87.5^{\circ}$ latitude and $\pm 180^{\circ}$ longitude ranges with spatial resolutions of $2.5^{\circ}$ and $5^{\circ}$, respectively. In this paper, the nearest grid $\left(70^{\circ} \mathrm{W}, 20^{\circ} \mathrm{S}\right)$ to the epicenter was selected as the point to analyze. Although the GIM time-resolution is $2 \mathrm{hr}$, here values have been interpolated at $15 \mathrm{~min}$ intervals for easy comparison with the VTEC derived from 14 GPS stations.

Solar and geomagnetic activities and significant variations in the space weather strongly affect ionospheric perturbations. The $10.7 \mathrm{~cm}$ solar flux (F10.7) provided by NOAA National Geophysical Data Center was used to represent the solar activity. The equatorial geomagnetic activity index (Dst) and the global geomagnetic activity index $(\mathrm{Kp})$ provided by the World Data Center for Geomagnetism, Kyoto were used to represent the geomagnetic activity.

\subsection{VTEC anomaly analysis}

The sliding interquartile range method was adopted to detect ionospheric anomalies occurring before the Chile earthquake. We considered previous studies [5, 24, 25] and that the length of time window is limited by the seasonal variability of the ionosphere at longer timescales. 15 days was chosen as the length of a sliding time window. To be used as a background value, the median $\bar{x}$ was computed using the VTEC at the same time of each of the 15 days. The associated interquartile range, IQR was also obtained in order to construct the upper bound $\bar{x}+1.5 I Q R$ and the lower bound $\bar{X}-1.5 I Q R$. If an observed VTEC falls outside the associated bounds, a positive or negative abnormal signal is identified. To avoid detecting other short lifetime perturbations caused by some other geophysics such as thunderstorm, traveling ionospheric disturbances, ionospheric bubbles, and so on, an anomalous day was considered when observed VTEC continuously exceeded the associated upper or lower bounds for at least 6 hours during a day.

Figure 2 illustrates VTEC variations over the ABRA station, the nearest station to the epicenter, from 22 March to 1 April 2014. It can be observed that many positive abnormal signals of VTEC occurred within days 0-10 before the earthquake, and especially prominent increases appeared on 22-23 and 28-29 March 2014. Considering the criterion for identifying an anomalous day, positive anomalies occurred on 28 March over the ABRA station, 4 days before the earthquake. Figure 3 
displays the results of VTEC anomalies over the YCBA station. The temporal distribution of the positive anomalies over YCBA was similar to those over ABRA. It can be seen from Figures 2 and 3 that a significant increase in VTEC between 13:00 and 19:00 UTC (8:00 and 14:00 LT) appeared on 28 March. VTEC variations over the other 12 stations were also analyzed and the characteristics of VTEC anomalies were generally similar to those over ABRA and YCBA. Considering that there are GPS data gaps in some stations, VTEC variations occurring 7 days before the earthquake over the other 12 GPS stations were plotted (Figure 4). The number of stations over which positive VTEC anomalies occurred was counted (Figure 5), and it reveals that obvious positive anomalies can be observed generally 4 days before the earthquake.

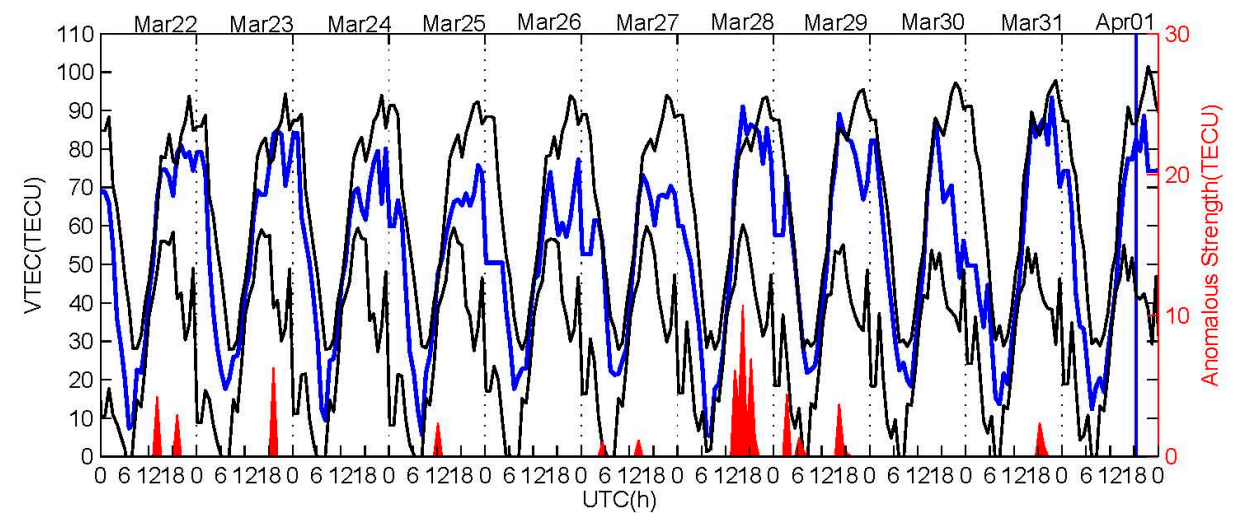

Figure 2. VTEC variations over ABRA station from 22 March to 1 April. The blue solid line denotes the VTEC time series, the red line denotes median $\bar{X}$, the black solid line denotes $\bar{X} \pm 1.5 I Q R$; the blue vertical line denotes the time of Chile earthquake occurrence. The red or black shaded areas represent the increase or decrease anomalous strength.

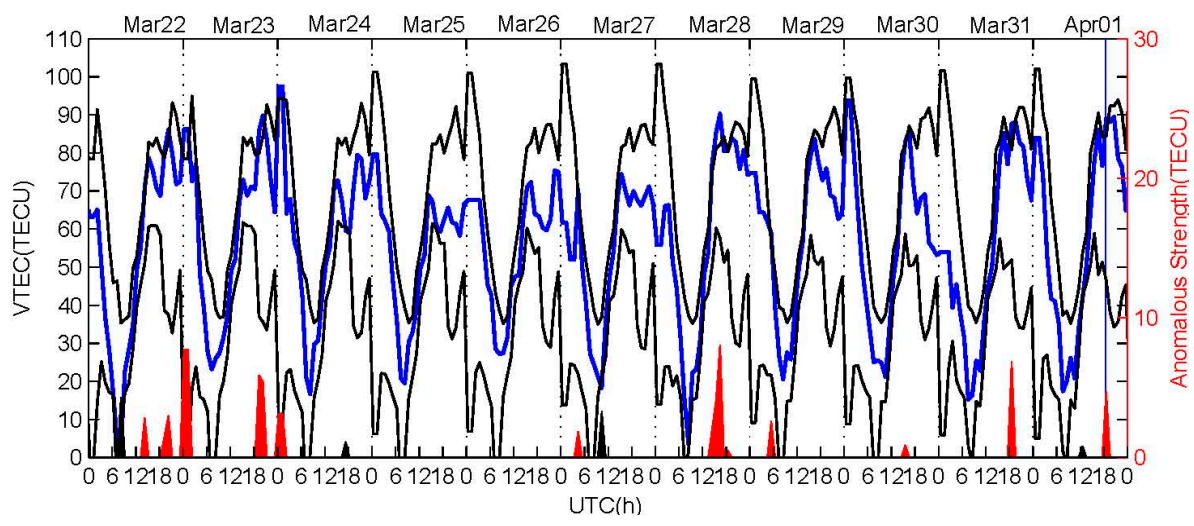

Figure 3. VTEC variations over YCBA station from 22 March to 1 April. The caption is same as that of Figure 2.

Since the nearest GPS station from which VTEC is derived is about $600 \mathrm{~km}$, GIM VTEC variations over the epicenter were also investigated. GIM VTEC along the longitude of the epicenter $\left(70^{\circ} \mathrm{W}\right)$ from 17 March to 1 April 2014 was shown in Figure 6. Obviously, VTEC between approximately $30^{\circ} \mathrm{S}$ and $10^{\circ} \mathrm{S}$ along the epicenter longitude increased on 23 and $28 \mathrm{March}$, and was higher during 12:00-20:00 UTC on 28 March. GIM VTEC variations were analyzed using the sliding interquartile range method (Figure 7). Figure 7(a) illustrates GIM VTEC variations over the grid point $\left(70^{\circ} \mathrm{W}, 20^{\circ} \mathrm{S}\right)$ nearest to the epicenter. Positive anomalies appeared on 23 and $28 \mathrm{March}$, and especially remarkable VTEC anomalies between 12:00 and 18:00 UTC (7:00 and 13:00 LT) occurred on 28 March. This result is also consistent with the GPS VTEC data (Figures 2-5). Moreover, the northward VTEC gradients were selected to detect the ionospheric anomalies before the earthquake. Figure 7(b) reveals that the northward VTEC gradients over the epicenter yield significant positive anomalies on 28 March, which is similar to Figure 7(a). Both GIM and GPS observations indicate that positive VTEC anomalies occurred on 28 March 2014. 


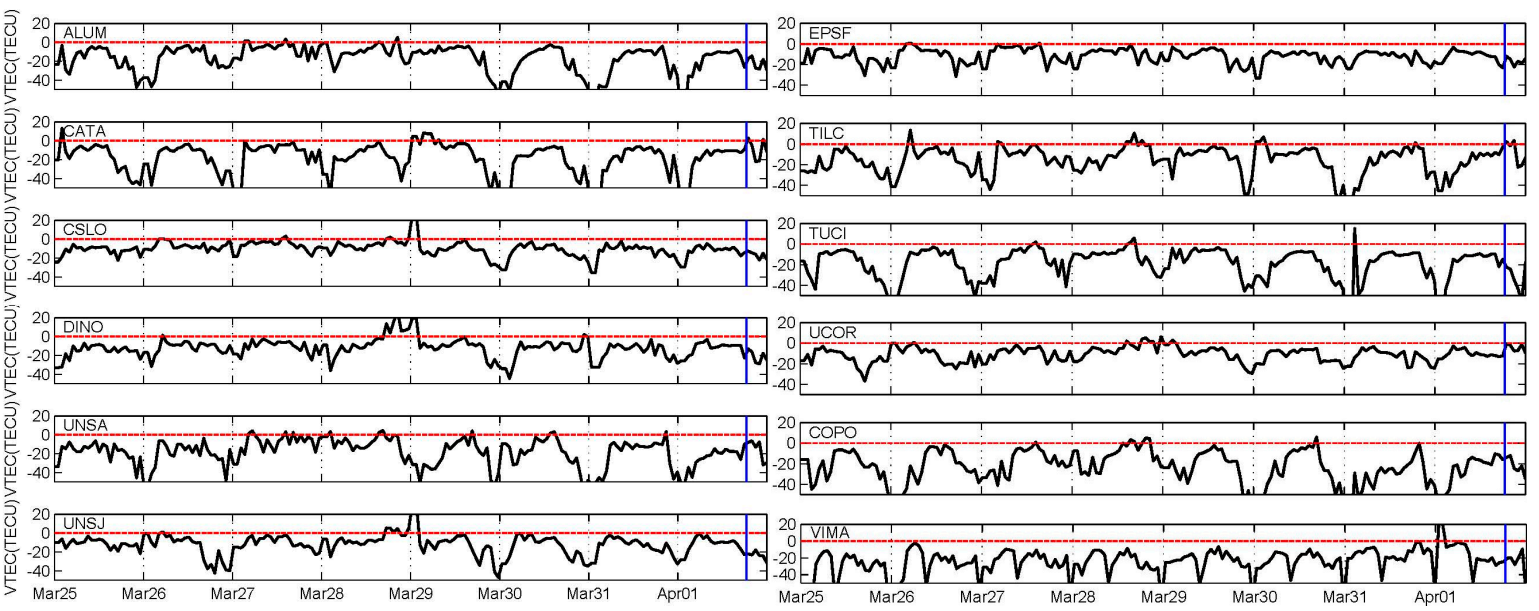

Figure 4. VTEC variations over 12 stations during 25 March to 1 April, the black solid line denotes $V T E C-(\bar{X}+1.5 I Q R)$, and the blue vertical line denotes the time of Chile earthquake occurrence.

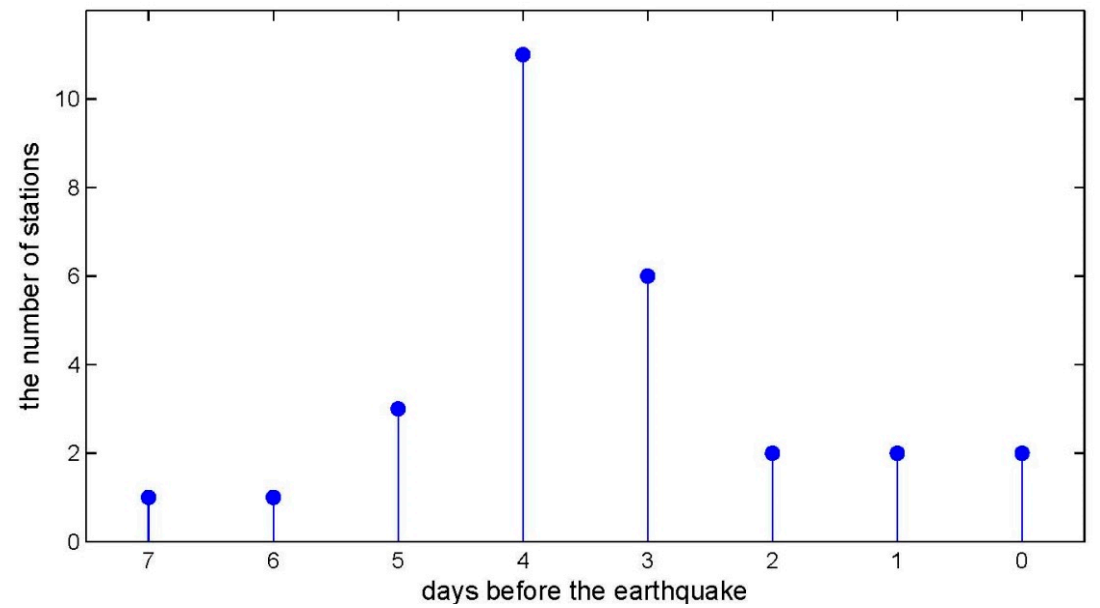

Figure 5. The number of stations over which appeared positive VTEC anomalies was counted on each day.
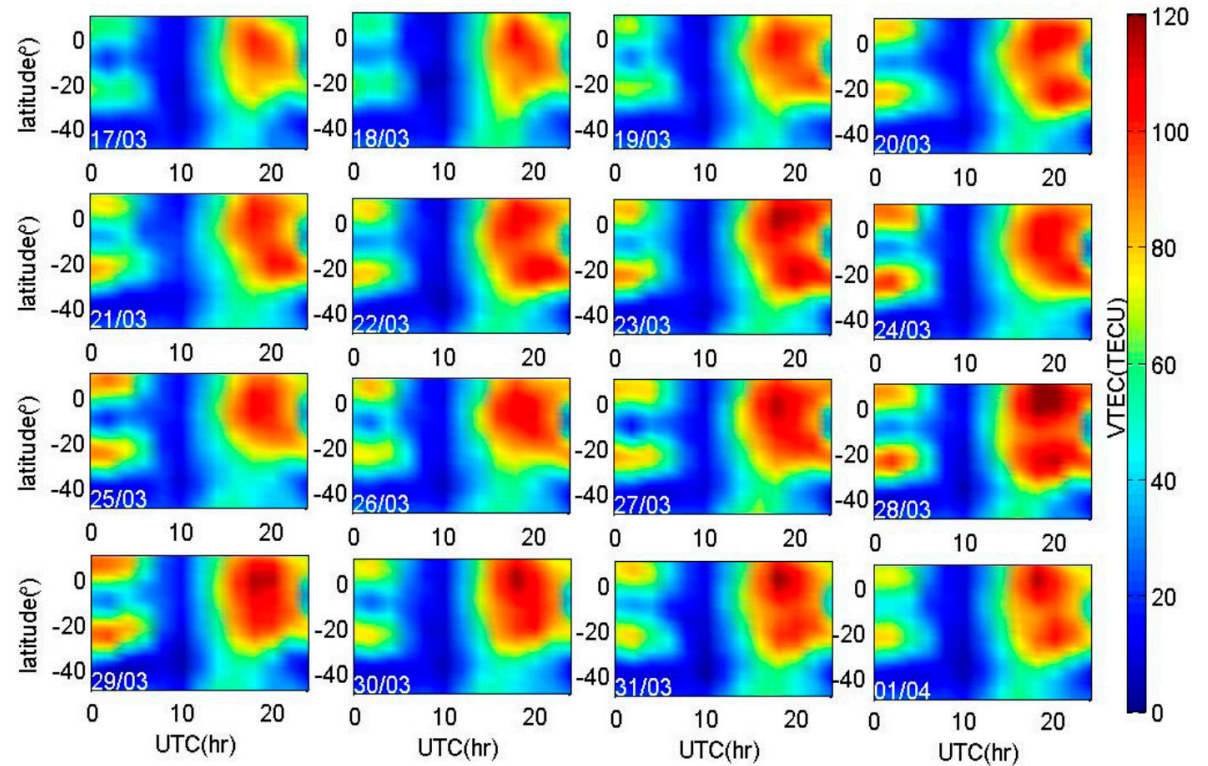

Figure 6. GIM VTEC along the Chile earthquake longitude $70^{\circ} \mathrm{W}$ from 17 March to 1 April 2014. 
(a) GIM VTEC variations over the grid point $\left(70^{\circ} \mathrm{W} ; 20^{\circ} \mathrm{S}\right)$

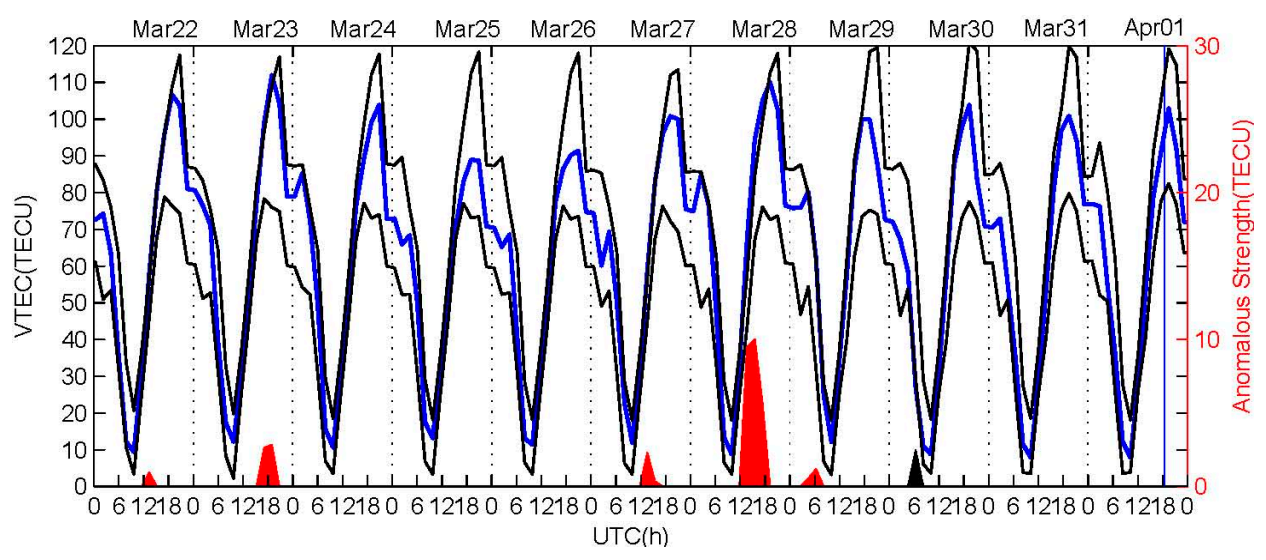

(b) Northward VTEC gradients $\left(70^{\circ} \mathrm{W}\right)$

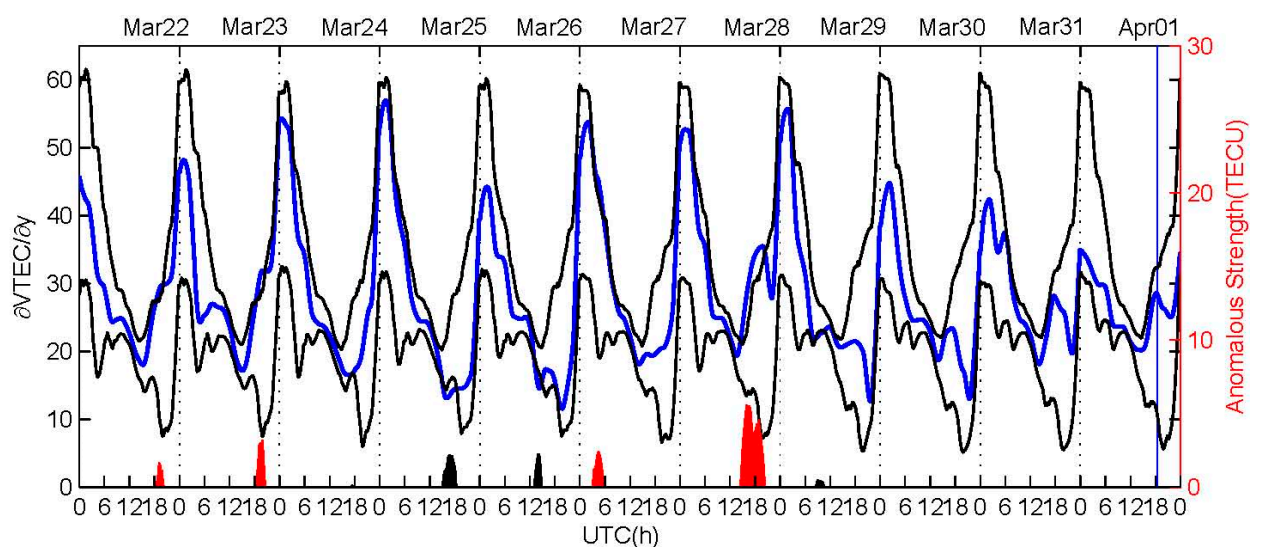

Figure 7. Temporal variations of GIM VTEC and the northward gradients from 22 March to 1 April 2014. The blue lines denote the observations, and the black lines denote the associated upper and lower bounds. The blue vertical lines denote the time of Chile earthquake occurrence. The red or black shaded areas represent the increase or decrease anomalous strength. In the bottom panel, the unit in y axis is TECU in $5^{\circ}$.

\section{Discussion}

To date, there have been some reports on ionospheric anomalies preceding the 2014 Chile earthquake. Akhoondzadeh adopted median and Artificial Neural Network methods using the GIM to detect the ionospheric anomalies before this Chile earthquake [26]. Akhoondzadeh found that marked positive VTEC anomalies were observed 4 days before the earthquake at 14:00 and 16:00 UTC using the median method, while the ANN method identified more anomalies, 4 (2:00 and 16:00 UTC) and 13 (24:00 UTC) days prior to the earthquake. Guo et al. utilized TEC and foF2 data to analyze ionospheric variations prior to $2014 \mathrm{Mw} 8.2$ earthquake in Chile, and the results showed that negative and positive TEC anomalies detected by a sliding interquartile range method over the CLLA station appeared on the 15th and 5th before the earthquake respectively, and foF2 over Jicamarca, Concepcion and Ramey stations presented significant positive anomalies 5 days preceding the earthquake [27]. It can be clearly seen that the result of [26] is consistent with that of this work, and there are some differences between the results of [27] and those of both [26] and this study. It should be noted that [27] adopted 27-day window, while [26] and this work used 15-day window. However, an investigation of the effects of the length of time window is beyond the scope of this article. Considering significant positive anomalies occurring on the 4th day before the earthquake, we focus on discussing whether these anomalies are related to the earthquake in the following sections. 


\subsection{Effects of solar and geomagnetic activities}

As the ionosphere is mostly affected by solar and geomagnetic activities, we first determined whether these significant anomalies could be attributed to high solar radiation and/or geomagnetic storms. The three conditions of $\mathrm{Kp}<4,|\mathrm{Dst}|<40 \mathrm{nT}$ and $\mathrm{F} 10.7<150$, are firstly used to distinguish pre-earthquake anomalies from the other anomalies related to solar and geomagnetic activities. If a day has F10.7 $>150$, then this day is removed from the analysis. The day and the following 3 days are also excluded whenever $|\mathrm{Dst}|>40 \mathrm{nT}$ [5]. Figure 8 illustrates the variations of Dst, Kp and F10.7 indices from 17 March to 1 April 2014. There were slight geomagnetic disturbances on 31 March $(\mathrm{K} p>3)$, and the geomagnetic situation was rather quiet on the other days. F10.7>130 revealed that solar activities were in a relatively unquiet condition during this time, and F10.7 exceeded 150 on 20 26 March, 31 March and 1 April, indicating severe solar radiation. Furthermore, as shown in Figure 9, we analyzed the pre-earthquake solar activity by the sliding interquartile range method and found that there were no significant F10.7 anomalies. Considering the solar activities on 23 March, it suggests that these positive anomalies are mainly caused by the intense solar activities. There are comparatively quiet solar and geomagnetic activities on $28 \mathrm{March}$; it is suggested that these positive VTEC anomalies are weakly associated with high solar activities and geomagnetic storms.
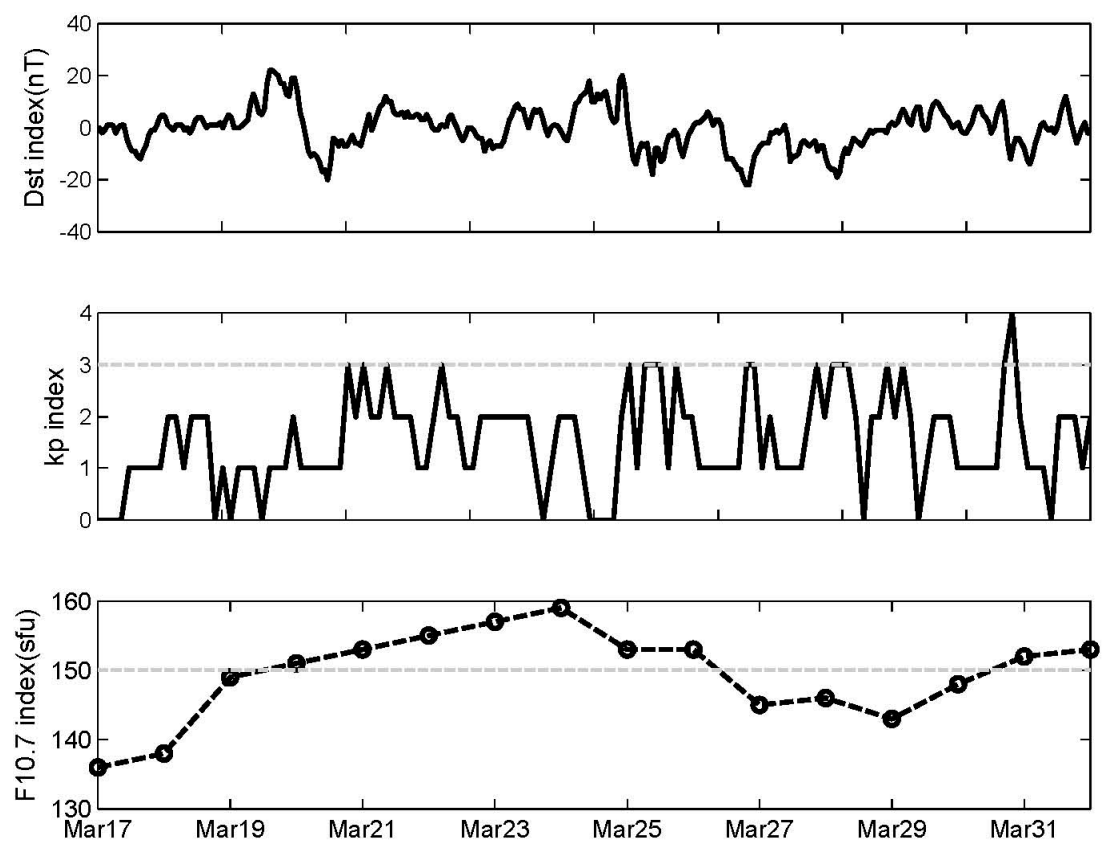

Figure 8. Variations of the Dst, Kp and F10.7 indices from 17 March to 1 April 2014. The grey dashed lines denote the threshold values.

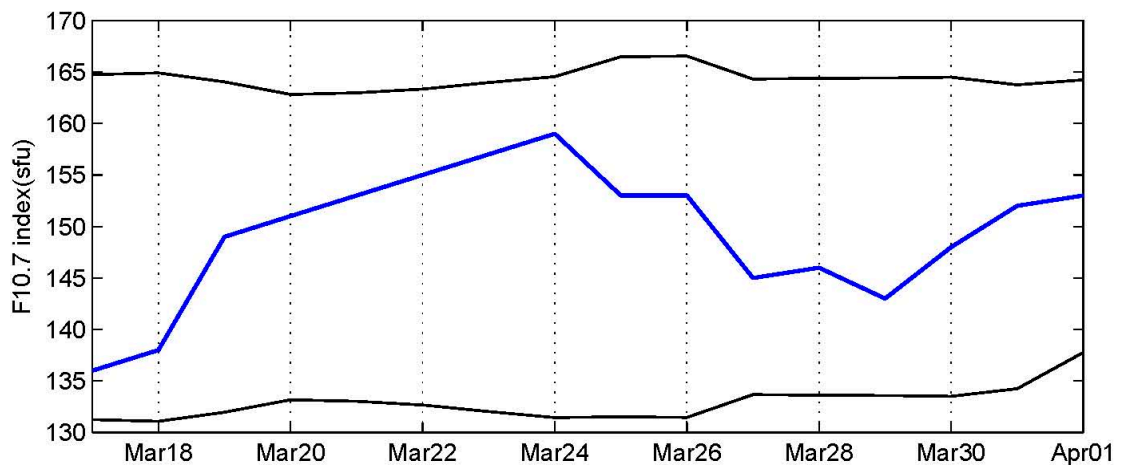

Figure 9. Variations of the F10.7 indices from 17 March to 1 April 2014. The blue line denotes the observations, and the black lines denote the associated upper and lower bounds. 


\subsection{Spatiotemporal distribution of VTEC anomalies}

To examine whether the positive anomalies specifically appeared 4 days before the 2014 Chile earthquake, VTEC over the epicenter during 17 to 31 March in 2009-2014 was analyzed using the same method described in Sect. 2.2. Also, VTEC for a full year before the earthquake was analyzed. Moreover, the influence of solar and geomagnetic activities was corrected for using the same criterion as described in Sect. 3.1.

Figure 10 shows that positive anomalies occur on 28 March 2014, 31 March 2011, 18 March 2010 and 20 March 2009, respectively. There were quiet solar and geomagnetic activities during 17 to 31 March in 2009-2011, but an Mw5.4 earthquake $\left(19.27^{\circ} \mathrm{S}, 69.70^{\circ} \mathrm{W}\right)$, an Mw5.9 earthquake $\left(19.75^{\circ} \mathrm{S}\right.$, $\left.69.51^{\circ} \mathrm{W}\right)$ and an Mw6.1 earthquake $\left(28.11^{\circ} \mathrm{S}, 71.31^{\circ} \mathrm{W}\right)$ occurred on 27 March 2009, 2 April 2011 and 26 March 2010, respectively. However, we do not intend to discuss whether these anomalies are related to these earthquakes in this study. Moreover, as shown in Figure 11, there were some VTEC anomalies occurring from 1 March 2013 to 31 March 2014. We examined the earthquake catalogue during this time, and found that all VTEC anomalies appeared before the Mw>5.0 earthquakes occurring at the similar location. Also, we do not intend to discuss whether the anomalies appeared during 1 March 2013 to 31 March 2014 are related to these earthquakes in this paper. As shown in Figures 10 and 11, it could be observed that the VTEC anomalies seem not to be normal seasonal and diurnal variations. Therefore, it is suggested that the VTEC anomalies on 28 March 2014 may be mainly induced by other factors, such as the subsequent earthquake. As we know, 28 March is near to the autumn/spring $(\mathrm{SH} / \mathrm{NH})$ equinox when VTEC is at one of the two semi-annual maximum. However, VTEC over the epicenter also increased obviously on 23 March 2014 (e.g., Figures 6 and 7) which is much nearer to the autumn/spring $(\mathrm{SH} / \mathrm{NH})$ equinox, and the positive anomalies occurred on 28 March were more significant than those occurred on 23 March (Figure 7); it seems that VTEC at the semi-annual maximum value is not the main cause of the remarkable positive anomalies appearing on 28 March 2014.

As discussed above, there were significant positive VTEC anomalies occurring on 28 March 2014. We removed the contributions from solar and geomagnetic activities and discussed the temporal distribution of VTEC anomalies; the results suggest that the observed VTEC anomalies might mainly have been produced by the forthcoming Chile earthquake. In order to examine the spatial distribution of these positive anomalies, global ionospheric VTEC anomalies around midday (11:00 13:00LT) were plotted on 28 March 2014 (Figure 12). It is clear that the affected area mainly ranged from $20^{\circ} \mathrm{S}$ to $30^{\circ} \mathrm{S}$ in latitude and $70^{\circ} \mathrm{W}$ to $100^{\circ} \mathrm{W}$ in longitude. The corresponding ionospheric effects could be observed in the magnetically conjugate region. The location of the maximally affected area in the ionosphere did not coincide with the vertical projection of the epicenter, but was instead to the south, which was further westwards. The ionospheric anomalies preceding the earthquakes occurred not only over the epicenter but also in the nearby regions and sometimes also in magnetically conjugated regions of the ionosphere [28-30]. Moreover, there were no significant or similar VTEC anomalies occurring in the rest of the world at the same time. We know that ionospheric anomalies caused by the space environment generally occur over a wider geographic range. However, the observed positive anomalies occur only near the epicenter, providing further evidence that the ionospheric VTEC anomalies observed on 28 March may be associated with the Chile earthquake.

In addition, to conclude the temporal characteristics of the anomalies, we statistically investigated the variations of GIM VTEC over $67 \mathrm{Mw} \geq 6.0$ earthquake epicenters (Figure 1) over the $\left(6^{\circ}-39^{\circ} \mathrm{S} ; 60^{\circ}-78^{\circ} \mathrm{W}\right)$ area from 1 January 2004 to 31 December 2013 . The ionospheric VTEC anomalies preceeding each earthquake are identified; the influences of solar and geomagnetic activities have been removed. The result shows that VTEC anomalies appeared before 42 of 67 earthquakes in Chile from 1 January 2004 to 31 December 2013. To further examine the temporal characteristics of these VTEC anomalies, the 67 earthquakes were divided into 5 categories according to their magnitudes, ranging from $M w \geq 6.0$ to $M w \geq 6.8$ at a 0.2 interval. Figure 13 summarizes those cumulative percentages of the positive or negative anomaly over the 15 days before these classified earthquakes. The percentage is given as the cumulative count of the anomalies divided by the number of the 
earthquakes. Figure 13 reveals that positive anomalies appear more frequently than negative ones and that the percentage of positive anomalies seems to be proportional to the earthquake magnitude over 10 days before the earthquakes. However, because the number of earthquakes decreases over time, that trend of the percentage of positive anomalies becomes increasingly ambiguous. Note that the temporal characteristics of the ionospheric anomalies preceding earthquakes over the $\left(6^{\circ}-39^{\circ} S\right.$; $\left.60^{\circ}-78^{\circ} \mathrm{W}\right)$ area are complex due to the presence of various fault zones, which should be studied in greater detail in the future.
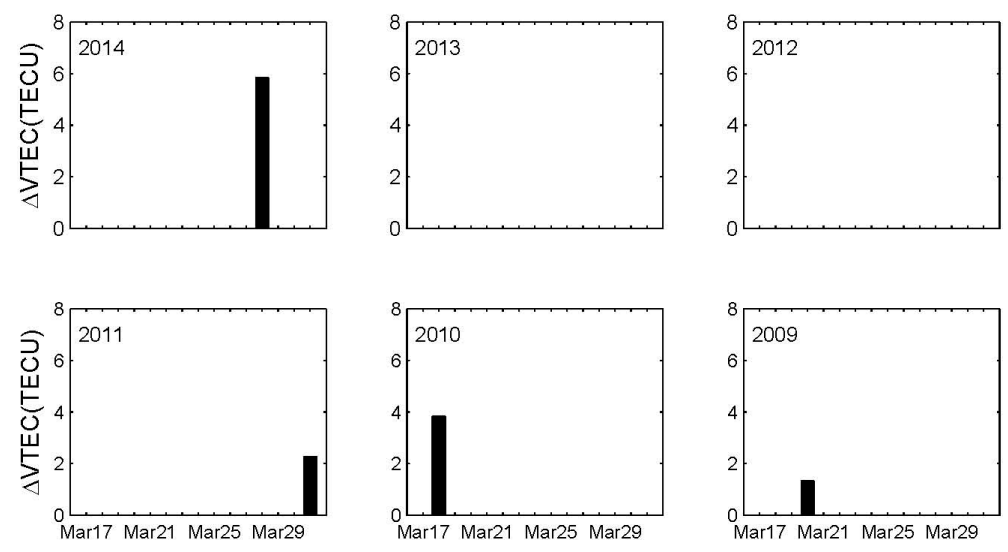

Figure 10. The anomaly days observed from 17 March to 31 March in 2009 2014. The bars indicate the maximum departures of the observations and upper bounds.

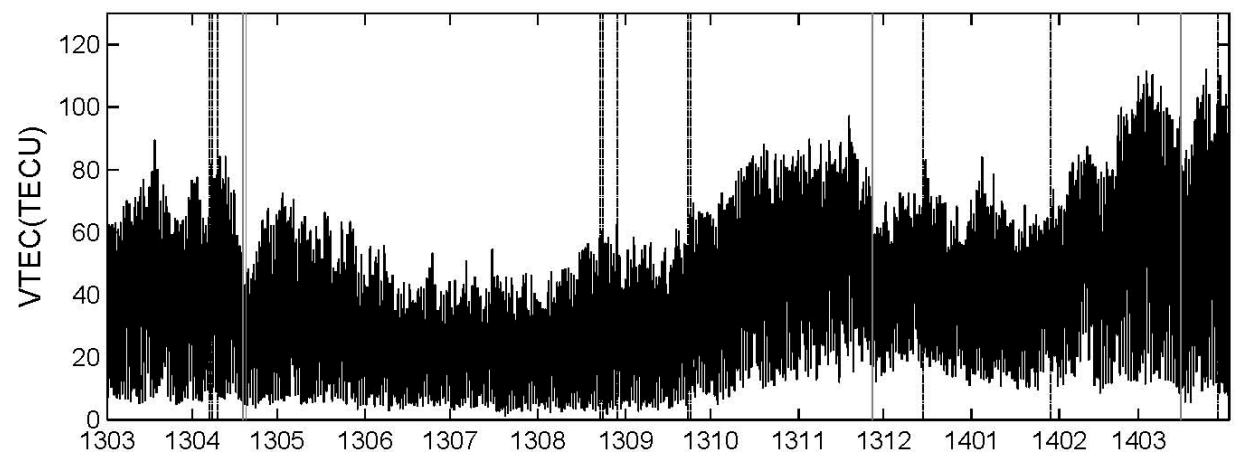

Figure 11. VTEC time series over the grid point $\left(70^{\circ} \mathrm{W}, 20^{\circ} \mathrm{S}\right)$ from 1 March 2013 to 31 March 2014. The black and gray vertical lines denote the positive and negative anomalies, respectively.
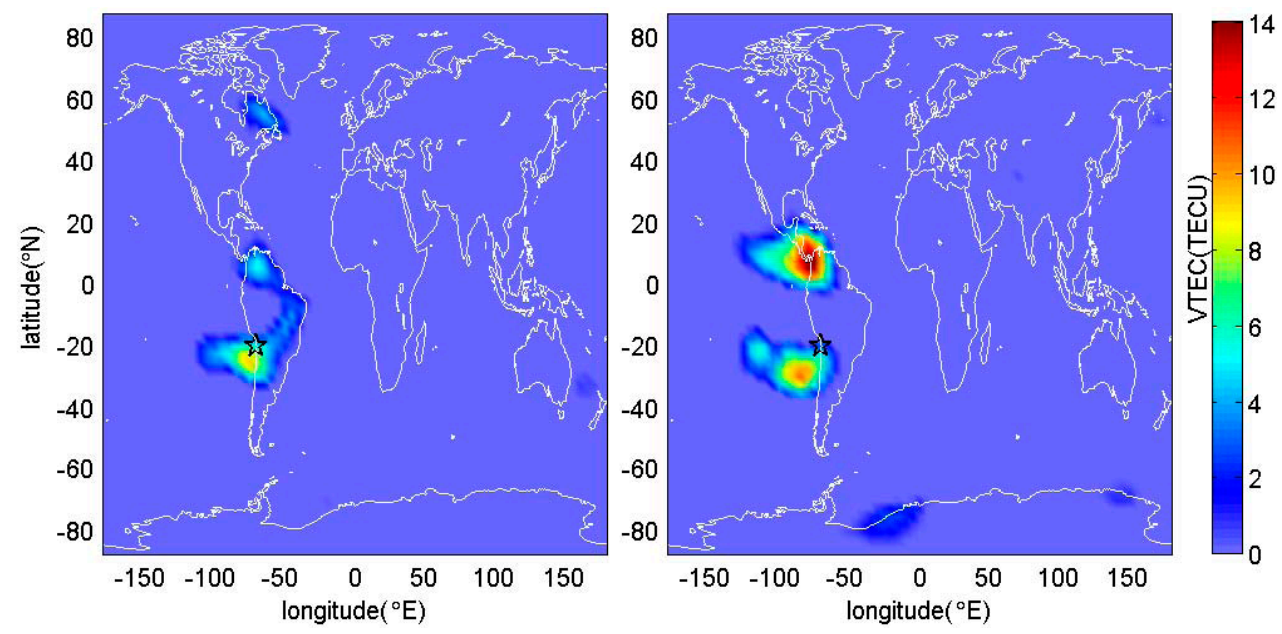

Figure 12. Spatial distributions of global ionospheric VTEC anomalies $($ VTEC $-(\bar{X}+1.5 I Q R))$ around midday (11:00 13:00 LT). The black star denotes the epicenter. 


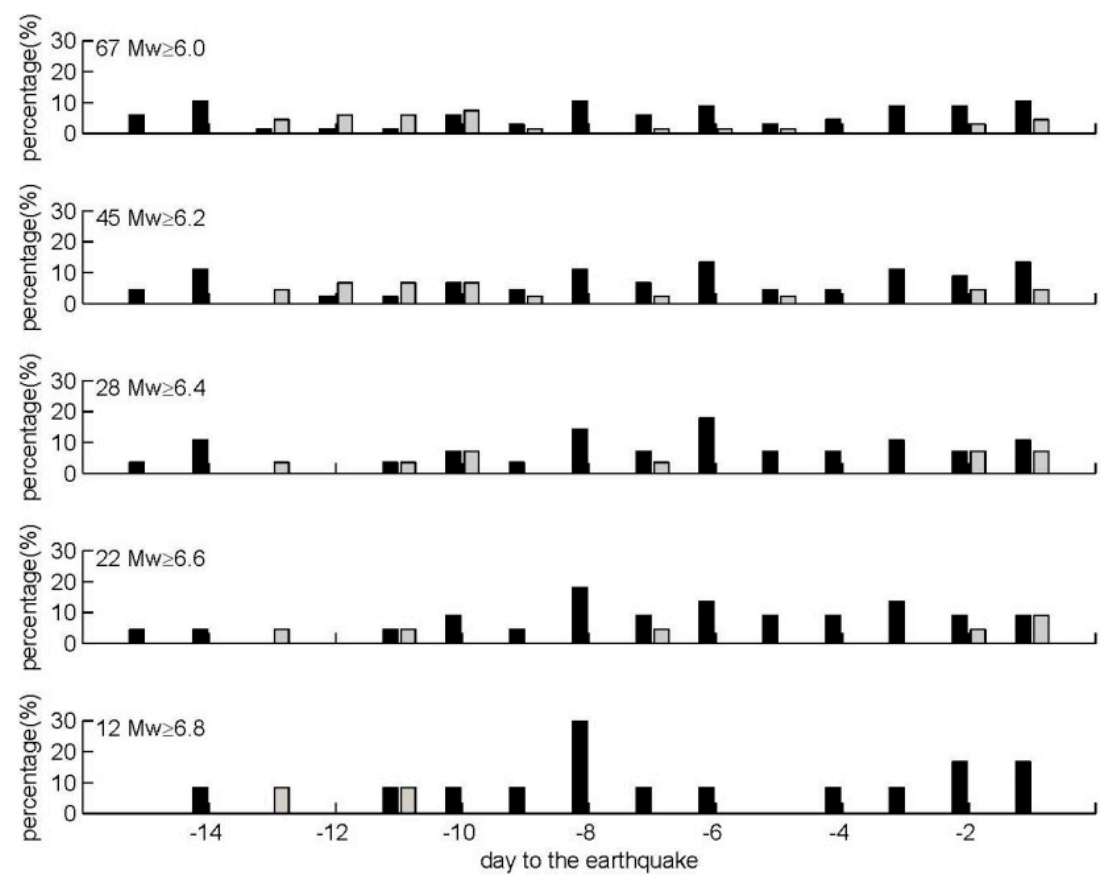

Figure 13. Percentages of the positive (black) and negative (grey) anomalies over the epicenter for 15 days prior to the $67 \mathrm{Mw} \geq 6.0$ earthquakes over $\left(6^{\circ}-39^{\circ} \mathrm{S} ; 60^{\circ}-78^{\circ} \mathrm{W}\right)$ area during 2004 to 2013.

\subsection{Equatorial anomaly dynamics}

The equatorial anomaly is a double-humped structure in the geomagnetic latitudinal distribution of ionosphere electron densities with crests on both sides of the magnetic equator and a trough near the magnetic equator. The equatorial anomaly is the effect of a dynamo eastward electric field generated by the atmospheric tides near the magnetic equator where the magnetic field is horizontal [31]. Generally, the equatorial anomaly appears in the morning, reaches its greatest development in the post noon and then gradually disappears. The epicenter of the 2014 Chile earthquake is approximately located on the $11^{\circ} \mathrm{S}$ geomagnetic, which is near the southern crest of the ionospheric equatorial anomaly. Thus, the upper atmospheric (or ionospheric) electric field in the earthquake preparation area is essential to the equatorial anomaly. Similarly, Taiwan lies between the $10^{\circ} \mathrm{N}$ and $14^{\circ} \mathrm{N}$ geomagnetic near the northern crest of the equatorial anomaly. Liu et al. statistically analyzed the variations of equatorial ionization anomaly (EIA) of the $150 \mathrm{M} \geq 5.0$ earthquakes during 2001-2007 in Taiwan, and the results showed the EIA crest moved significantly equatorward or poleward during the earthquakes along the Taiwan longitude, which was probably due to the atmospheric electric fields generated around the epicenter of a subsequent earthquake during the preparation period [31]. Quite a few studies have demonstrated that disturbances of the equatorial anomaly along the longitudes of the epicenters occurred before the earthquakes, suggesting that the anomalous electric fields generated in the earthquake preparation area caused the ionospheric anomalies. Zakharenkova et al. analyzed ionospheric effects of the 26 December 2004 Indonesia earthquake and 26 September 2005 Peru earthquake, the results showed that the perturbations of the equatorial anomaly occurred a few days before the earthquakes, which suggests that the anomalous electric fields in the earthquake preparation zone were a possible cause of the observed ionospheric anomalies [32-33]. Pulinets et al. studied the dynamics of the equatorial anomaly at $105^{\circ} \mathrm{E}$ before the Wenchuan earthquake, and found that the shape of the equatorial anomaly was distorted, which made it possible to state that the observed anomalies were caused by additional electric fields [30].

Thus, the spatiotemporal distributions of the equatorial anomaly from 17 March to 1 April 2014 along the longitude of the epicenter $70^{\circ} \mathrm{W}$ were monitored (Figure 14) in this study. To better illustrate the variations of the equatorial anomaly, geographical latitudes have been converted to 
geomagnetic latitudes in Figure 14. The significant modification of the equatorial anomaly on 28 March can be observed: (a) the VTEC in the equatorial anomaly generally increased; and (b) the shape of the VTEC distribution was distorted, and a double-humped structure appeared with the southern crest near the epicenter and the trough near the magnetic equator. Obviously, the VTEC distribution is usually a crest appearing near the magnetic equator at 11:00 LT along $70^{\circ} \mathrm{W}$, but unusually enhanced on 28 March 2014 (Figure 14). It is known that the equatorial anomaly reacts sensitively to the changes in the electric field. In the case of the preparatory stage of the earthquake, there might be a penetration of abnormal electric fields of seismogenic origin into the ionospheric heights, which strengthens or weakens the natural field of equatorial electrojet and causes the VTEC disturbances. Moreover, Figure 12 reveals that the positive anomalies mainly lie on the two crests of the equatorial anomaly, suggesting that the anomalous electric field may be a possible cause of the observed anomalies, for the electric field disturbances could cause both the anomalies over the epicenter and at the magnetically conjugated location. Namgaladze et al. proposed that anomalous eastward electric fields in the earthquake preparation area led to the upward movement of plasma and its transition to the area with lower densities of $\mathrm{O} 2$ and N2. Consequently, the disappearance rate of $\mathrm{O}+$ in the ionospheric $\mathrm{F} 2$ region decreased, the electron density increased, and the equatorial anomaly enhanced [34]. This mechanism might account for the ionospheric positive anomalies and the perturbations of the equatorial anomaly occurring 4 days prior to the Chile earthquake.

However, as shown in Figures 12 and 14, it can be clearly seen that the anomalies near the epicenter appeared in the side far away the equator on 28 March, instead of the side closer to the equator. Pulinets proposed that the meridional wind which comes from the summer hemisphere to the winter one could lead to the seasonal asymmetry; the charged component of the neutral wind could cause the winter crest of the equatorial anomaly to increase [35]. After the spring equinox, because of the movement of the location of direct solar radiation, the southern crest is similar to the winter crest of the equatorial anomaly in comparison with the northern crest. The neutral wind can easily blow the plasma particles moving along to the magnetic field lines, thereby the winter crest TEC increasing, which might also be a reason for TEC anomalies that are closer to the southern crest of the equatorial anomaly in Figures 12 and 14.
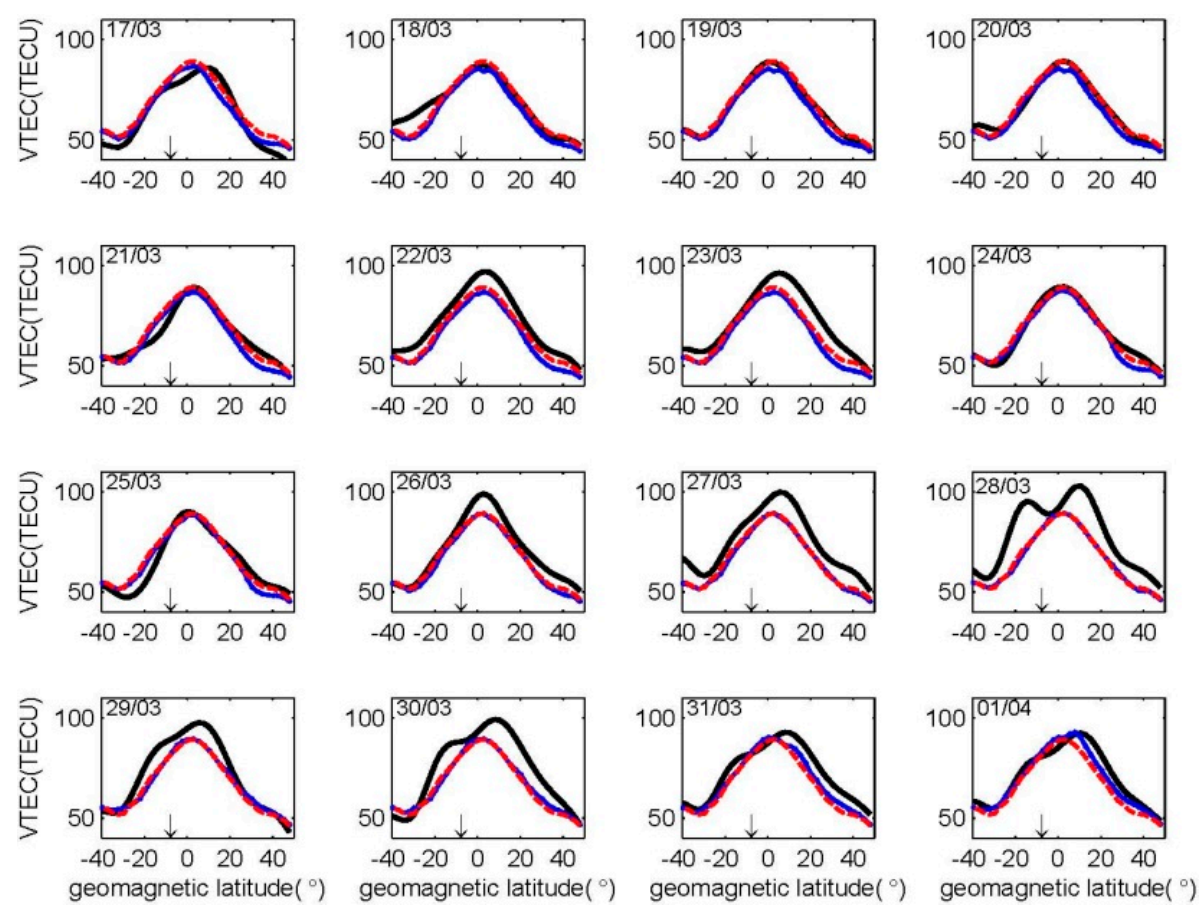

Figure 14. VTEC variations along $70^{\circ} \mathrm{W}$ from 17 March to 1 April 2014. The black line denotes VTEC observations. The red line denotes the median value in March. The blue line denotes the median value calculated by VTEC at the same time during previous 15 days. The black arrow denotes the geomagnetic latitude of the epicenter. 


\section{Conclusions}

By utilizing data from 14 GPS stations, VTEC time series were obtained. The sliding interquartile range method was used to analyze the VTEC variations over each station, and the results indicate that significant positive VTEC anomalies occurred 4 days before the earthquake. Meanwhile, GIM VTEC and its northward gradients were used to cross-examine the ionospheric variations. The results show that GIM VTEC over the nearest grid and the associated northward gradients both increased significantly 4 days prior to the earthquake.

To investigate the causes of the observed VTEC anomalies, the effects of solar and geomagnetic activities were analyzed. The result indicates that the anomalies appearing on 28 March 2014 are slightly associated with high solar activities and geomagnetic storms. After removing the influences of solar and geomagnetic activities, we investigated the temporal distribution of VTEC anomalies. The anomalous variations of VTEC were analyzed from 17 March to 1 April in 2009-2013. Also, VTEC for a full year before the earthquake was studied. The results suggest that the positive anomalies occurring on 28 March 2014 may be related to factors such as the Chile earthquake. In addition, a statistical analysis of VTEC anomalies before $67 \mathrm{Mw} \geq 6.0$ earthquakes around Chile during 2004 to 2013 was performed. The results show that VTEC anomalies occurred before 42 of 67 earthquakes around Chile during 2004 to 2013. However, the characteristics of the temporal distribution of these anomalies need to be further studied. Furthermore, we investigated the characteristics of the spatial distribution of VTEC anomalies, and found that the observed VTEC anomalies occurred between $20^{\circ} \mathrm{S}$ and $30^{\circ} \mathrm{S}$ and $70^{\circ} \mathrm{W}$ and $100^{\circ} \mathrm{W}$, showing a conjugate structure that did not appear in the rest of the world at this time. Considering the analysis and discussion of the spatiotemporal distributions of the VTEC anomalies, we can suggest that the positive VTEC anomalies occurring on 28 March may be associated with the Chile earthquake.

Moreover, we initially examined the physical mechanism of the positive VTEC anomalies by analyzing the equatorial anomaly variations along $70^{\circ} \mathrm{W}$, and found that the equatorial anomaly increased on 28 March 2014. Considering the spatial distribution of anomalies along with the perturbations to the equatorial anomaly, we suggest that anomalous electric fields generated in the earthquake preparation area and the meridional wind are possible causes of the observed ionospheric anomalies occurring before the 2014 Chile earthquake. However, the physical mechanism needs to be further studied in the future.

Acknowledgments: We are grateful to Instituto Geográfico Nacional (IGN) from Argentine for providing GPS data, the NOAA National Geophysical Data Centre for providing solar F10.7 flux, the World Data Centre for Geomagnetism, Kyoto providing Dst index and geomagnetic Kp index, the Global CMT Project providing the parameters of the earthquakes, and IGS providing GIM. We thank Fabrizio Masci and Alberto J. Foppiano for the helpful comments on the manuscript very much. This research was supported by the National Natural Science Foundation of China (Grant No. 41525014, 41374033 and 41210006), the Program for Changjiang Scholars of the ministry of education of China, and The German Academic Exchange Service project (Grant No. 57173947).

Author Contributions: Weiping Jiang and Yifang Ma performed the analyses and prepared the paper. Xiaohui Zhou provided the technical guidance to the implementation of the sliding interquartile range method. Zhao Li contributed to the discussion on the physical mechanism. Xiangdong An and Kaihua Wang helped the plotting of the figures.

Conflicts of Interest: The authors declare no conflict of interest.

\section{References}

1. Leonard R. S.; Barnes R. A. Observation of ionospheric disturbances following the Alaska earthquake. J. Geophys. Res. 1965, 70, 1250-1253.

2. Liu, J. Y.; Chen, Y. I.; Chuo, Y. J.; Tsai, H. F. Variations of ionospheric total electron content during the Chi-Chi earthquake. Geophys. Res. Lett. 2001, 28, 1383-1386.

3. Liu, J. Y.; Tsai, Y. B.; Chen, S. W.; Lee, C. P.; Chen, Y. C.; Yen, H. Y. Giant ionospheric disturbances excited by the M9.3 Sumatra earthquake of 26 December 2004. Geophys. Res. Lett. 2006, 33, 356-360. 
4. Pulinets, S.; Boyarchuk, K.; Lomonosov, A.; Liu, J. Y. Ionospheric Precursors to Earthquakes: A Preliminary Analysis of the foF2 Critical Frequencies at Chung-Li Ground-Based Station for Vertical Sounding of the Ionosphere (Taiwan Island). Geomagn. Aeronomy 2002, 42, 508-513.

5. Le, H. J.; Liu, J. Y.; Liu, L. A statistical analysis of ionospheric anomalies before 736 M6.0+ earthquakes during 2002-2010. J. Geophys. Res. 2011, 116, doi:10.1029/2010JA015781.

6. Zhu F.; Zhou Y.; Lin J.; Su F. A statistical study on the temporal distribution of ionospheric TEC anomalies prior to M7.0+ earthquakes during 2003-2012. Astrophys. Space Sci. 2014, 350, 449-457.

7. Tang J.; Yao Y.; Zhang L. Temporal and Spatial Ionospheric Variations of 20 April 2013 Earthquake in Yaan, China. IEEE Geosci. Remote S. 2015, 12, 2242-2246.

8. Sun, Y. Y.; Liu, J. Y.; Lin, C. Y.; Tsai, H. F.; Chang, L. C.; Chen, C. Y. Ionospheric f2 region perturbed by the 25 April 2015 Nepal earthquake: ionosphere perturbed by Nepal earthquake. J. Geophys. Res. 2016, 121, doi: 10.1002/2015JA022280.

9. Zhou, Y.; Wu, Y.; Qiao, X.; Zhang, X. Ionospheric anomalies detected by ground-based GPS before the Mw7.9 Wenchuan earthquake of May 12, 2008, China. J. Atmos. Sol-terr. Phy. 2009, 71, 959-966.

10. Yao, Y.; Chen, P.; Wu, H.; Zhang, S.; Peng, W. Analysis of ionospheric anomalies before the $2011 \mathrm{Mw} 9.0$ Japan earthquake. Chinese Sci. Bull. 2012, 57, 500-510.

11. Ho, Y. Y.; Jhuang, H. K.; Su, Y. C.; Liu, J. Y. Seismo-ionospheric anomalies in total electron content of the GIM and electron density of DEMETER before the 27 February 2010 M8.8 Chile earthquake. Adv. Space Res. 2013, 51, 2309-2315.

12. Rishbeth H. Ionoquakes: Earthquake Precursors in the Ionosphere? Eos Transactions American Geophysical Union 2006, 87, 316-316.

13. Dautermann T.; Calais E.; Haase J.; Garrison, J. Investigation of ionospheric electron content variations before earthquakes in southern California, 2003-2004. J. Geophys. Res. 2007, 112, doi:10.1029/2006JB004447.

14. Masci, F. The study of ionospheric anomalies in Japan area during 1998-2010 by Kon et al.: An inaccurate claim of earthquake-related signatures? J. Asian Earth Sci. 2012, 57, 1-5.

15. Ovalle, E. M.; Bravo, M. A.; Villalobos, C. U.; Foppiano, A. J. Maximum electron concentration and total electron content of the ionosphere over Concepción, Chile, prior to the 27 February 2010 earthquake. Adv. Space Res. 2013, 52, 1274-1288.

16. Masci, F; Thomas J. Comment on "Temporal and spatial precursors in ionospheric total electron content of the 16 October 1999 Mw7.1 Hector Mine earthquake”, by Su et al. (2013). J. Geophys. Res. 2014, 119, 69946997.

17. Kon S.; Nishihashi M.; Hattori K. Ionospheric anomalies possibly associated with $\mathrm{M} \geq 6.0$ earthquakes in the Japan area during 1998-2010: Case studies and statistical study. J. Asian Earth Sci. 2011, 41, 410-420.

18. He, L.; Wu, L.; Pulinets, S.; Liu, S.; Yang, F. A nonlinear background removal method for seismo-ionospheric anomaly analysis under a complex solar activity scenario: A case study of the M9.0 Tohoku earthquake. Adv. Space Res. 2012, 50, 211-220.

19. Le, H.; Liu, L.; Liu, J. Y.; Zhao, B.; Chen, Y.; Wan, W. The ionospheric anomalies prior to the M9.0 Tohoku-Oki earthquake. J. Asian Earth Sci. 2013, 62, 476-484.

20. Liperovsky, V. A.; Pokhotelov, O. A.; Meister, C. V.; Liperovskaya, E. V. Physical models of coupling in the lithosphere-atmosphere-ionosphere system before earthquakes. Geomagn. Aeronomy 2008, 48, 795-806.

21. Pulinets S.; Ouzounov D. Lithosphere-Atmosphere-Ionosphere Coupling (LAIC) model-An unified concept for earthquake precursors validation. J. Asian Earth Sci. 2011, 41, 371-382.

22. Klimenko, M. V.; Klimenko, V. V.; Zakharenkova, I. E.; Pulinets, S. A. Variations of equatorial electrojet as possible seismo-ionospheric precursor at the occurrence of TEC anomalies before strong earthquake. Adv. Space Res. 2012, 49, 509-517.

23. Hernández-Pajares, M.; Juan, J. M.; Sanz, J.; Orus, R.; Garcia-Rigo, A.; Feltens, J. The IGS VTEC maps: a reliable source of ionospheric information since 1998. J. Geod. 2009, 83, 263-275.

24. Liu, J. Y.; Chuo, Y. J.; Shan, S. J.; Tsai, Y. B.; Chen, Y. I.; Pulinets, S. A. Pre-earthquake ionospheric anomalies registered by continuous GPS TEC measurements. Ann. Geophys. 2004, 22, 1585-1593.

25. Liperovskaya, E. V.; Bogdanov, V. V.; Biagi, P. F.; Meister, C. V.; Liperovsky, V. A. Day-time variations of foF2 connected to strong earthquakes. Nat. Hazards Earth Syst. Sci. 2009, 9, 53-59.

26. Akhoondzadeh M. Investigation of GPS-TEC measurements using ANN method indicating seismo-ionospheric anomalies around the time of the Chile $(\mathrm{Mw}=8.2)$ earthquake of 01 April 2014. Adv. Space Res. 2014, 54, 1768-1772. 
27. Guo, J.; Li, W.; Yu, H.; Liu, Z.; Zhao, C.; Kong, Q. Impending ionospheric anomaly preceding the Iquique Mw8.2 earthquake in Chile on 2014 April 1. Geophys. J. Int. 2015, 203, 1461-1470.

28. Ruzhin Y.; Larkina V.; Depueva A. Earthquake precursors in magnetically conjugated ionosphere regions. Adv. Space Res. 1998, 21, 525-528.

29. Pulinets, S. A.; Legen'Ka, A. D.; Gaivoronskaya, T. V.,; Depuev, V. K. Main phenomenological features of ionospheric precursors of strong earthquakes. J. Atmos. Sol-terr. Phy. 2003, 65, 1337-1347.

30. Pulinets, S. A.; Bondur, V. G.; Tsidilina, M. N.; Gaponova, M. V. Verification of the concept of seismoionospheric coupling under quiet heliogeomagnetic conditions, using the Wenchuan (China) earthquake of May 12, 2008, as an example. Geomagn. Aeronomy 2010, 50, 231-242.

31. Liu, J. Y.; Chen, C. H.; Chen, Y. I.; Yang, W. H.; Oyama, K. I.; Kuo, K. W. A statistical study of ionospheric earthquake precursors monitored by using equatorial ionization anomaly of GPS TEC in Taiwan during 2001-2007. J. Asian Earth Sci. 2010, 39, 76-80.

32. Zakharenkova I. E.; Krankowski A.; Shagimuratov I. Modification of the low-latitude ionosphere before the 26 December 2004 Indonesian earthquake. Nat. Hazard Earth Sys. 2006, 6, 817-823.

33. Zakharenkova, I. E.; Shagimuratov, I. I.; Tepenitzina, N. Y.; Krankowski, A. Anomalous modification of the ionospheric total electron content prior to the 26 September 2005 Peru earthquake. J. Atmos. Sol-terr. Phy. 2008, 70, 1919-1928.

34. Namgaladze, A. A.; Klimenko, M. V.; Klimenko, V. V.; Zakharenkova, I. E. Physical mechanism and mathematical modeling of earthquake ionospheric precursors registered in total electron content. Geomagn. Aeronomy 2009, 49, 252-262.

35. Pulinets, S. A. Low-latitude atmosphere-ionosphere effects initiated by strong earthquakes preparation process. International Journal of Geophysics 2012, 2012, doi: 10.1155/2012/131842.

(C) 2017 by the authors. Licensee Preprints, Basel, Switzerland. This article is an open access article distributed under the terms and conditions of the Creative Commons by Attribution (CC-BY) license (http://creativecommons.org/licenses/by/4.0/). 